\title{
Fuentes documentales para la historia de la discapacidad en el Archivo Histórico Nacional
}

\author{
Documentary sources for a history of disability in the National History \\ Archives
}

\section{Palabras clave \\ Fuentes documentales, historia de la discapacidad, Archivo Histórico Nacional.}

\section{Keywords}

Documentary sources, history of disabiity, National History Archives.

1. Introducción

Este artículo tiene su origen en la visita que realizaron el presidente y otros miembros del Comité Español de Representantes de Personas con Discapacidad (CERMI) al Archivo Histórico Nacional (AHN) en el mes de abril de 2021. Con motivo de esta visita, los archiveros del AHN prepararon una muestra de documentos en los que aparecieran representadas las personas con discapacidad y las instituciones que, desde la Edad Media a la Contemporánea, han asumido la asistencia a las mismas, con el propósito de ofrecer una primera aproximación a las fuentes documentales para la historia de la discapacidad conservadas en este archivo. A esta selección inicial de documentos se han añadido algunos más para esta publicación.

La concepción de la discapacidad y la situación social de las personas con discapacidad ha cambiado notablemente a lo largo de la historia, desde un modelo denominado como tradicional o de la prescindencia, que relegaba a las personas con discapacidad a una situación de exclusión, segregación y marginación, a otro en el que aquéllas dejan de ser consideradas inútiles por la sociedad en la medida en que consigan ser rehabilitadas y normalizadas, hasta la última etapa, la más reciente en la conceptualización de la discapacidad, la cual, basada en la autonomía personal y la autodeterminación, tiene como meta compartida por todos los agentes sociales la inclusión y la igualdad de derechos (López, 2019, pp. 837-844).

La selección documental suponía un reto, toda vez que a nadie se le ocultan las dificultades que presenta la búsqueda de información sobre grupos

\section{Belén de Alfonso Alonso- Muñoyerro \\ <belen.alfonso@cultura.gob.es> \\ Archivo Histórico Nacional. España}

\section{Eva Bernal Alonso}

<eva.bernal@cultura.gob.es>

Archivo Histórico Nacional. España

José Luis Clares Molero

$<$ jluis.clares@cultura.gob.es>

Archivo Histórico Nacional. España

\section{Cecilia Martín Moreno}

<cecilia.martin@cultura.gob.es>

Archivo Histórico Nacional. España

\section{Enrique Pérez Boyero}

<enrique.perez@cultura.gob.es>

Archivo Histórico Nacional. España

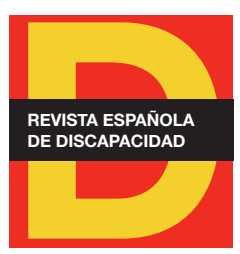

Para citar:

de Alfonso, B. et al. (2021). Fuentes documentales para la historia de la discapacidad en el Archivo Histórico Nacional. Revista Española de Discapacidad, 9(1), pp. 205-214.

Doi: <https://doi.org/10.5569/23405104.09.02.12> 
humanos marginados históricamente. A la escasez y dispersión de las fuentes documentales se suma otro inconveniente derivado de su naturaleza, la distorsionada imagen que proyectan de las personas con discapacidad, pues estas siempre aparecen como meros agentes pasivos, carentes de voz propia. En efecto, la práctica totalidad de las referencias documentales encontradas proceden de los archivos de las instituciones benéficas o de los poderes públicos en el ejercicio de sus funciones de protección y control social del colectivo de personas con discapacidad.

Por otro lado, dada la heterogeneidad de este grupo social, la muestra debía atender cuestiones como los distintos tipos de discapacidad (física, sensorial, intelectual), su origen (congénita o sobrevenida a causa de un accidente o un acto de violencia), su carácter temporal o permanente, y el grado o estado de afectación (leve o grave) de las facultades del individuo. Debemos señalar que se han respetado los términos con los que aparecen designados en la documentación los individuos que tienen alguna discapacidad, aunque hoy día se consideren peyorativos: "lisiado”, “manco”, “cojo", "tullido”, “inválido”, “inútil”, "deforme”, “enfermo”, "deficiente", "demente", "loco", "anormal”, etc.

\section{La Edad Media}

Este periodo de la historia se caracteriza por la influencia del cristianismo en todos los aspectos de la vida política, económica, social y cultural. La posición social frente a la discapacidad en esta etapa, fuertemente influida por la Iglesia, fue ambivalente. Por un lado, aunque los concilios y la legislación canónica condenaban el infanticidio, la discapacidad podía ser interpretada como el resultado del pecado original o la obra del diablo, por lo que muchas personas con discapacidad, consideradas "deformes", "defectuosas" o "endemoniadas", sufrían el rechazo y eran perseguidas por las autoridades civiles y eclesiásticas, acabando con frecuencia en la hoguera. Por otro lado, la discapacidad se contemplaba como la obra de Dios, convirtiéndose en objeto de misericordia y caridad cristiana, de modo que las personas que la tienen son receptoras de obras benéficas por parte de los buenos cristianos, que las realizan como un medio para alcanzar la salvación (Andrés, 2018). En consecuencia, durante el medievo y los siglos siguientes proliferan por toda la cristiandad fundaciones e instituciones de carácter asistencial (asilos, hospicios, hospitales, colegios), promovidas por particulares, corporaciones e instituciones eclesiásticas, pertenecientes al clero regular y secular, para recoger a los menesterosos, entre los cuales se encuentran las personas con discapacidad.

El AHN custodia, en el grupo de fondos de instituciones eclesiásticas desamortizadas, más de dos mil fondos documentales del clero regular, tanto de órdenes masculinas como femeninas; cerca de un centenar de fondos de catedrales y más de dos mil de iglesias parroquiales, colegiatas y ermitas; y 110 fondos de hospitales pertenecientes a distintas instituciones pías y asistenciales. El volumen de documentos de este grupo de fondos asciende a 9697 legajos, 21.045 libros y 4075 carpetas de pergaminos (de la Cruz, 2003). En esta enorme masa de documentos se puede encontrar una variada tipología documental (actas fundacionales, reglamentos, actas de visitas, cuentas, expedientes personales de asistentes y asistidos, libros registro, inventarios de bienes y enseres, correspondencia, etc.), que contiene abundante información sobre fundaciones e instituciones benéficas en las que fueron asistidas muchas personas con discapacidad. Con esta información se puede estudiar la historia socioeconómica de la asistencia social, los usos de la beneficen- 
cia, sus objetivos y multitud de aspectos relacionados con la vida de los asistidos, entre quienes se hallaban numerosas personas con discapacidad, no sólo durante la Edad Media sino también en la Edad Moderna.

Un ejemplo destacado del interés que para la historia de la discapacidad tienen los fondos documentales antes mencionados lo tenemos en el manuscrito, redactado en torno a 1550, con instrucciones para enseñar a hablar, leer, escribir y contar a sordomudos. Elaboradas por fray Pedro Ponce de León, monje benedictino del monasterio de San Salvador de Oña (Burgos), constituyen un ejemplo pionero que, venciendo resistencias importantes, abrieron camino a la educación de los sordomudos'.

Las instituciones eclesiásticas no son las únicas que asumen la responsabilidad de subvenir a las personas con discapacidad. Como se apuntó anteriormente, también las corporaciones (concejos y comunidades de villa y tierra) jugaron un papel destacado en la asistencia social durante la Edad Media. Ejemplo de ello son las asignaciones o pensiones que otorgaron a los vecinos que habían sufrido mutilaciones en los conflictos bélicos en los que se vieron envueltos los habitantes de las aldeas, villas y ciudades medievales. Es el caso de un grupo de vecinos de la comunidad de aldeas de Daroca (Zaragoza) a comienzos del siglo XV, que, en el transcurso de las guerras fronterizas entre las Coronas de Castilla y Aragón, habían sido apresados por los castellanos y mutilados de una mano, recibiendo una compensación monetaria (20 sueldos jaqueses de plata) por parte de dicha comunidad. Este tipo de compensaciones por mutilaciones sufridas en combate o como castigo impuesto a los cautivos eran frecuentes. En la serie de albaranes del archivo de la comunidad de aldeas de Daroca se cuentan hasta un total de 13 documentos de este tipo concedidos entre 1402 y 1418 , cifra muy elevada para la época ${ }^{2}$. El archivo de la comunidad de aldeas de Daroca se conserva en el $\mathrm{AHN}$, en el grupo de archivos privados, de corporaciones y colecciones.

\section{La Edad Moderna}

Durante los siglos XVI y XVII, pero, sobre todo, a partir del XVIII, comienza a desvincularse progresivamente la discapacidad de la demonología (López, 2019, p. 841). Los avances registrados en cirugía y medicina (como la técnica para ligar las arterias a los muñones en las amputaciones, el uso de fórceps y suturas para cerrar las heridas o la utilización de prótesis y aparatos ortopédicos) transformaron poco a poco la conciencia social respecto a algunos tipos de discapacidad y se empezó a pensar en la posibilidad de que las personas que las tenían pudieran llevar una vida "normal" si se les proporcionaban los medios adecuados (Andrés, 2018). Por otra parte, el humanismo renacentista comenzó a poner en tela de juicio los paradigmas antropológicos y pedagógicos sostenidos hasta entonces. Los nuevos tiempos empezarán el edificio de la educación no tanto por la sublimación y transmisión de valores tradicionales como por el redescubrimiento del hombre como sujeto y principio de educación. Ya no se trataba tanto de reformar la naturaleza encaminándola a los valores de la tradición, se tratará sobre todo de perfeccionarla desde sus propias circunstancias individuales. Este principio abrirá unas posibilidades inusitadas a aquellos colectivos que hasta entonces no habían tenido acceso a la

1. AHN, CLERO-SECULAR REGULAR, 1319. Este documento fue objeto de "La Pieza del Mes" de febrero de 2020 del Archivo Histórico Nacional. Elaborada por Elena Jiménez López, puede consultarse en el siguiente enlace: https://www.culturaydeporte.gob.es/cultura/areas/archivos/mc/ archivos/ahn/ofertas-pedagogicas/la-pieza-del-mes/2020/febrero-2020.html.

2. AHN, DIVERSOS-COMUNIDADES, Car. 54, N. 20. 
educación, como es el caso de las personas con discapacidad. A diferencia de lo sucedido en el medievo, la existencia de pobres y menesterosos, aunque formara parte de la existencia del mal en el mundo, podía mitigarse y erradicarse. Los humanistas del XVI, los arbitristas del XVII y los ilustrados del XVIII tendrán una visión optimista y en no pocas ocasiones utópica: para ellos el mal puede mitigarse e incluso erradicarse y ser vencido. Por ello, proponen una panoplia de medidas legislativas, culturales y asistenciales para incorporar a los pobres y a los desprotegidos a la sociedad (Vergara, 2002, p. 138).

A medida que avanza el siglo XVIII, comienza a tomar fuerza la idea de que debía existir una responsabilidad social hacia las personas con discapacidad. La llustración hará recaer esta responsabilidad sobre el Estado, que empezará a asumir competencias en los ámbitos de la educación y de la beneficencia, obligaciones que antes no tenía o que abandonaba en manos de los particulares y de otras instituciones como las corporaciones o la Iglesia. El Estado absolutista, pues, entra de lleno en la reglamentación jurídica y organización de la asistencia social. El Libro VII (títulos XXXVII y XXXVIII) de la Novísima Recopilación aborda los diversos centros asistenciales (casas de expósitos, hospitales, hospicios y casas de misericordia), regulando su régimen y funcionamiento con todo detalle (Maza, 1987, pp. 163-175).

El Estado asume la supervisión de los centros asistenciales, incluso de aquellos que han sido fundados por particulares, corporaciones (cofradías, concejos) o instituciones eclesiásticas, para evitar abusos o dejaciones de responsabilidad. Ejemplo de ello es el expediente del Consejo de Castilla sobre la reunión y arreglo de los hospitales de la ciudad de Córdoba y su obispado (1815-1820); y el expediente incoado a instancia de Francisco Grimaud de Velarde por el que solicita licencia a dicho Consejo para establecer un instituto destinado a la enseñanza de los ciegos de ambos sexos ${ }^{4}$.

Del mismo modo, y con idéntica finalidad, se fiscalizan y controlan las cofradías y hermandades, bajo cuyo amparo se encontraban muchas personas con discapacidad. Sirva de ejemplo el expediente del Consejo de Castilla (1766-1831) sobre la modificación y aprobación de las ordenanzas para el régimen y gobierno de la Hermandad Obra Pía de la Visitación de Nuestra Señora Santa Isabel y Ánimas del purgatorio sita en el Convento del Carmen Calzado de Madrid, que agrupaba a los ciegos que vendían en la calle almanaques, gacetas y otros papeles de devoción y diversión 5 ; o el dictamen del mismo Consejo de 1748 sobre el memorial presentado por la Cofradía de Ciegos de Valencia solicitando vender privativamente las gacetas, romances e impresos de a pliego y medio pliego, y que se les exima del pago de derechos reales ${ }^{6}$.

En lo que respecta a la fiscalidad, los monarcas trataron de favorecer a las personas con discapacidad mediante la exención de bagajes, tributos reales y cargas concejiles, como la concedida a los ciegos por un privilegio otorgado por Isabel la Católica en 1487. Sin embargo, esta exención fue objeto de frecuentes reclamaciones por aquéllos ante las autoridades, que no siempre la respetaban, por lo que terminaban en pleitos ante las audiencias y el Consejo de Castilla. Es el caso de José Canelas, ciego y vecino del Puerto de Santa María, que pleitea en 1745 con el fiscal del Consejo de Hacienda por ese motivo ${ }^{7}$; y el de varios ciegos, vecinos de Santiago de Fontaneira (Lugo), Corral de Almaguer (Toledo), Abándames (Asturias) y Laciana (León), que solicitan al Consejo de Castilla en 1817 y 1818 la expedición de un documento con el que acreditar tal privilegio ${ }^{8}$.

3. AHN, CONSEJOS, 3537, Exp. 6.

4. AHN, CONSEJOS, 3618, Exp. 6.

5. AHN, CONSEJOS, 868, Exp. 30

6. AHN, CONSEJOS, 6839, Exp. 19.

7. AHN, CONSEJOS, 37694, Exp. 3221.

8. AHN, CONSEJOS, 3370, Exp. 2. 
Las autoridades reales persiguieron y castigaron los fingimientos por el perjuicio que causaban a los verdaderos receptores de la caridad. Ejemplo de ello es el expediente iniciado por el gobernador de las salas del crimen de la Audiencia y Chancillería de Granada (1792-1796) remitiendo al Consejo de Castilla documentación relativa a la causa contra Juan Bouche None, un francés detenido en las inmediaciones de Almuñécar y que se fingía mudo, sordo e insensible ${ }^{9}$.

Sin embargo, muchas veces eran las personas con discapacidad las perseguidas y castigadas por las autoridades civiles y eclesiásticas. Las personas ciegas fueron víctimas frecuentes de la represión ejercida por los tribunales inquisitoriales debido al modo de vida de muchos de ellos, que deambulaban por las calles y plazas de las villas y ciudades del reino mendigando y recitando romances o cantando coplas, que podían ser interpretadas como escandalosas, supersticiosas, blasfemas o heréticas. En los fondos de Inquisición se conservan numerosos procesos de fe contra ellos ${ }^{10}$.

Los monarcas del siglo XVIII impulsaron también las primeras medidas destinadas a asegurar una remuneración a los militares que quedaban inválidos como consecuencia de las heridas sufridas en las guerras. Felipe V promulga el 26 de octubre de 1717 el "Reglamento para el establecimiento de los Oficiales y Soldados de las Tropas destinadas a Inválidos y sueldos que respectivamente deben gozar", donde se disponía que con los oficiales y soldados impedidos que disfrutaban del sueldo de inválidos, se formaran compañías compuestas por dos capitanes, dos tenientes, dos subtenientes, tres sargentos y cien soldados. El 20 de diciembre de ese mismo año se promulga la "Real Ordenanza sobre la residencia, sueldos y disciplina de los Oficiales y Soldados inválidos o impedidos, incluso los de Reales Guardias”. Doce años más tarde, en 1729 se dispone por Real Orden que se considerase a las Unidades de Inválidos (Batallones) como unidades militares y en servicio. Por Real Orden de 7 de julio de 1732, los Batallones existentes pasan a convertirse en Regimientos y se crean compañías de inválidos hábiles y compañías de inválidos inhábiles. Aquellos que resultasen inutilizados en las dotaciones de los buques de la Armada y los que procedieran de los Batallones de Infantería y Marina también fueron incluidos.

Así pues, la intervención del Estado absolutista en relación con la discapacidad se manifiesta en la adopción de un variado conjunto de medidas y actuaciones, de todas las cuales tenemos ejemplos en la documentación custodiada en el AHN, donde se conserva una parte de la documentación producida por las instituciones de la monarquía española durante la Edad Moderna (Consejos, Juntas y Secretarías de Estado y del Despacho). A finales del siglo XIX fue la propia Administración quien hizo entrega al AHN de aquella documentación que los organismos del Antiguo Régimen no habían llegado a remitir al Archivo General de Simancas. Esta abundante documentación corresponde a la Cámara de Castilla y a los Consejos de CastiIla, Aragón, Cruzada, Estado, Hacienda, Indias, Inquisición y Órdenes; a Juntas como la de Incorporaciones, Beneficencia, Sanidad, etc.; y a las Secretarías de Estado y del Despacho de Estado y de Guerra y Hacienda; así como a la producida por los tribunales de distrito de la Inquisición. Un conjunto de 67.500 legajos, 6990 libros y 4588 mapas, planos y dibujos que, a medida que se avance en su organización y descripción, constituirá un depósito de información imprescindible para el conocimiento de la discapacidad en la Edad Moderna.

9. AHN, CONSEJOS, 1703, Exp. 24.

10. AHN, INQUISICIÓN, 2354, Exp. 7; 3726, Exp. 230; 200, Exp. 33; 211, Exp. 8; 205, Exp. 24; 1674, Exp. 5. 


\section{La Edad Contemporánea}

El proceso secularizador de la asistencia social en España, iniciado por los monarcas absolutistas en el siglo XVIII, terminará cristalizando en el nuevo régimen liberal a partir del segundo tercio del siglo XIX, tras los conatos fallidos de 1812 y del Trienio liberal (1820-1823). En efecto, en plena Guerra de la Independencia, las Cortes de Cádiz proyectan un plan asistencial y sanitario acorde con el pensamiento liberal. La Constitución de 1812 reclama para el Estado y los organismos públicos (artículo 321) la asunción y control de la asistencia social. Establece que serán los Ayuntamientos los encargados de cuidar y supervisar los hospitales, hospicios, casas de expósitos y demás establecimientos benéficos costeados por el común. Los centros asistenciales de patronato particular se regirán por sus estatutos, si bien sujetos a la inspección de los jefes políticos a fin de evitar abusos e irregularidades. El retorno en 1814 de Fernando VII y del absolutismo deroga este secularizador proyecto asistencial, al igual que todo el entramado constitucional gaditano. Un segundo intento tiene su marco en el Trienio liberal con la promulgación de la ley de 6 de febrero de 1822, que por primera vez en la historia española traza un completo plan organizativo de la beneficencia pública, fundamentado en la uniformidad administrativa y en la pretendida supresión de los centros benéficos particulares. Sin embargo, el prematuro cercenamiento del periodo constitucional anula otra vez estas disposiciones Tras la muerte de Fernando VII, una serie de disposiciones legales culminan en el restablecimiento de la ley general de beneficencia de 1822, que permanecerá en vigor hasta mediados del siglo XIX, aunque las instituciones benéficas particulares conservarán sus patrimonios y una importante autonomía económica (Maza, 1987, pp. 176-180).

A mediados del siglo XIX se acomete una nueva reorganización global de la beneficencia. La ley de 20 de junio de 1849 establece una división primordial entre la beneficencia pública y la privada, que continuará su desarrollo bajo el patrocinio de la iniciativa particular y de la Iglesia. Los centros públicos se clasifican en tres categorías: generales, provinciales y municipales, según los servicios prestados y el origen de sus recursos. La dirección de la beneficencia queda en manos del Ministerio de la Gobernación, a través de una Junta General de Beneficencia (auxiliar del gobierno en la dirección de los establecimientos generales). Las Juntas Provinciales y Municipales se encargan del gobierno y administración de los establecimientos provinciales y municipales. Por Real Decreto de 14 de mayo de 1852 se aprueba un minucioso Reglamento general para la ejecución de la mencionada ley. La importancia histórica de estas disposiciones no entraña dudas por permanecer en vigor, con ligeros retoques, hasta bien entrado el siglo XX. Entre estas modificaciones cabe señalar la desaparición (en el Sexenio democrático) de las Juntas de Beneficencia (General, Provinciales y Municipales), cuyas funciones directivas y administrativas pasan a ser competencia, respectivamente, de la Dirección General de Beneficencia, las Diputaciones provinciales y los Ayuntamientos (Maza, 1987, pp. 183-194).

Por otra parte, tras la promulgación de la Ley de Instrucción Pública de 1857, impulsada por Claudio Moyano, ministro de Fomento, el Estado quedaba obligado a proporcionar enseñanza a sordomudos y ciegos en establecimientos específicos, procurando que hubiese por lo menos una escuela de esta clase en cada distrito universitario, y que en las escuelas públicas de niños se atendiese, en cuanto fuera posible, a su educación (artículos 6 y 108). El establecimiento modelo para todo el país sería el Real Colegio de Sordomudos y Ciegos de Madrid, fundado en 1802 bajo el patrocinio de la Real Sociedad Económica Matritense de Amigos del País, y que en 1852 pasaría a depender del Ministerio de Fomento con el nombre de Colegio Nacional de Sordomudos y Ciegos (Burgos, 2005, pp. 183-187). 
Para estudiar la historia de la discapacidad en la época contemporánea a través de los fondos documentales conservados en el AHN se deberá acudir, en primer lugar, a los del Ministerio del Interior, denominado de la Gobernación desde 1835 a 1977, entre cuyas amplias atribuciones se encuentran la sanidad y la beneficencia, de las cuales se encargará la Dirección General de Beneficencia o de Beneficencia y Sanidad. Entre las competencias de este órgano directivo cabe mencionar la creación, supresión (prerrogativas estas últimas que extiende a la beneficencia particular), dotación, administración, régimen e inspección de los centros de patronato público, así como la supervisión de los de iniciativa privada, y la concesión de plazas y pensiones en ellos.

Las competencias y actuaciones administrativas en materia de sanidad, beneficencia y educación no sólo se extendieron sobre las provincias peninsulares e insulares (Baleares y Canarias), sino también sobre los territorios ultramarinos (Cuba, Puerto Rico, Santo Domingo y Filipinas). La dirección de los asuntos que afectaban a estos últimos correspondió al Ministerio de Ultramar desde 1863 a 1899, años de creación y supresión de dicho Ministerio, cuyos fondos documentales (6087 legajos y 885 libros) se conservan en el AHN.

Seguidamente se expondrá una relación de expedientes y documentos ilustrativos de todas estas competencias y actuaciones administrativas sobre discapacidad.

Entre las facultades de la Dirección General de Beneficencia estaba la concesión de plazas y pensiones en colegios de sordomudos y ciegos (como alumnos internos o externos), en manicomios y en otros establecimientos benéficos (hospitales, hospicios) a personas con discapacidad. Así, por ejemplo, en la visita realizada por los miembros del CERMI, se mostró el expediente de concesión en 1889 de una plaza de interno en el Colegio Nacional de Sordomudos y Ciegos de Madrid al niño ciego de ocho años Pablo Alcázar, hijo de un jornalero madrileño, que ya asistía como alumno externo pobre ${ }^{11}$; y el expediente de concesión de una plaza en la clase de pobre en el Manicomio de Santa Isabel de Leganés (Madrid) en 1875 a Manuel Villegas, "demente", que había ingresado en 1868 como pensionista de segunda clase, a solicitud de su madre, viuda de 74 años, que no podía afrontar los gastos de estancia de su hijo en dicha institución y adeudaba 2792 pesetas $^{12}$.

Como ya hemos apuntado, el gobierno se reserva en exclusiva la facultad de crear o suprimir establecimientos benéficos, prerrogativa que se extiende a la beneficencia particular. Es por ello por lo que Aniceto Legar Martínez hubo de presentar en 1889 al Ministerio de Ultramar un proyecto para la creación de una escuela de sordomudos y ciegos en Filipinas. El expediente resultante detalla la plantilla con que debía contar el centro y la titulación y conocimientos que debían poseer los docentes y el resto del personal ${ }^{13}$. Es el mismo caso que el de Francisco Dolz y Lloréns, ciego por accidente, que solicita (1891) el establecimiento en Puerto Rico de una escuela de sordomudos y ciegos, para la cual se postula como profesor y director ${ }^{14}$; o el de la Orden de Religiosos Hospitalarios de San Juan de Dios, que solicitan permiso para establecer un manicomio en Manila y se les ceda para tal fin el edificio de la fábrica de tabacos de Malobón ${ }^{15}$.

Los establecimientos benéficos solían instalarse en antiguos conventos, cuarteles y edificaciones de variado tipo que habían pasado a manos del Estado, de las diputaciones provinciales y de las corporaciones municipales por títulos diversos, por lo que se hacía necesario llevar a cabo obras para adaptarlos a sus

11. AHN, FC-M﹎INTERIOR, 1428, Exp. 3.

12. AHN, FC-M'INTERIOR, 200, Exp. 8.

13. AHN, FC-M ${ }^{\circ}$-ULTRAMAR, 474, Exp. 23.

14. AHN, FC-M'_ULTRAMAR,339, Exp. 61.

15. AHN, FC-M﹎_ULTRAMAR, 5346, Exp. 17. 
nuevas funciones. Es el caso del Palacio de Vista Alegre en Carabanchel (Madrid), cuyo expediente de obras de acondicionamiento para establecer allí el Asilo de Inválidos del Trabajo (1887-1888) se conserva entre los fondos documentales del Ministerio del Interior. A través de él se puede seguir todo el procedimiento administrativo de ejecución de las obras (presupuesto, subasta pública, pliego de condiciones técnicas, memoria y proyecto de obra) y se halla información sobre la situación del edificio, los materiales utilizados, así como los informes elaborados por los arquitectos de la Real Academia de Bellas Artes de San Fernando ${ }^{16}$. También se conserva el expediente de obras de acondicionamiento de otras partes del edificio para establecer el Colegio de Ciegos de Santa Catalina de los Donados (1898-1900) ${ }^{17}$. En los fondos del Ministerio de Ultramar se encuentra el proyecto de construcción de un manicomio en la isla de la Convalecencia (Filipinas) con el fin de separar a los enfermos mentales de los demás asilados en el Hospicio de San José de Manila. El expediente (1868-1895) acompaña antecedentes relativos al sostenimiento de dicho hospicio (subvenciones), reglamentos y cinco planos del manicomio proyectado ${ }^{18}$.

A veces, las instituciones que pretendían construir centros benéficos recurrían al Gobierno para poder alcanzar sus objetivos. Es el caso de la Diputación provincial de Alicante, que solicita la cesión de un terreno (denominado "Campamento de Rabasa") perteneciente al Ministerio de la Guerra para construir un manicomio. El expediente (del año 1932) se conserva entre los fondos del Ministerio de Hacienda, competente en la administración general de los bienes del patrimonio del Estado ${ }^{19}$. Ello demuestra que, para el estudio de la historia de la discapacidad, no basta con la consulta de los fondos documentales producidos por los departamentos ministeriales con atribuciones en materia de educación, beneficencia y sanidad, pues existe documentación de interés en otros como el de Hacienda.

En lo que respecta a la administración de los establecimientos, la documentación ofrece datos de interés para conocer su situación y las irregularidades que se producían en su gestión, que repercutían directamente en la calidad de la alimentación y en la atención que recibían las personas con discapacidad que vivían en ellos. Sirva de ejemplo el expediente incoado en 1887 a la Comisión Provincial de Beneficencia de Valladolid, que había solicitado autorización para adquirir varios artículos de consumo (pan, garbanzos, aceite, arroz, bacalao, patatas, vino, leña) para el manicomio, el hospital y el hospicio de dicha provincia, pero se le denegó al haberse detectado irregularidades en la tramitación ${ }^{20}$; o el caso del manicomio de Plasencia, en el que gracias a la denuncia de una enfermera (1927) se investigan los presuntos abusos cometidos por el diputado delegado y el administrador ${ }^{21}$.

En ocasiones, determinados asuntos relativos a la discapacidad afectan a distintos ministerios y se ponen de manifiesto las relaciones de cooperación entre ellos. Es el caso del expediente del Ministerio de la Gobernación iniciado en 1876 a instancia de Miguel Fernández Villabrille, que pedía extender la instrucción de sordomudos en las escuelas primarias de beneficencia de España y de sus territorios de ultramar con la Biblioteca de la Enseñanza especial de sordomudos y de ciegos. Fernández Villabrille, profesor en ese momento del Colegio de Santa Catalina (Madrid), dependiente de la Dirección General de Beneficencia del citado Ministerio, considera que su obra continuaba y perfeccionaba la iniciada por Ponce de León, Juan Pablo Bonet y Rodríguez Pereira, entre otros. El Ministerio de la Gobernación la recomendaría a los Ministerios de

16. AHN, FC-M'INTERIOR, 2027, Exp. 5.

17. AHN, FC-M'_INTERIOR, 267, Exp. 9.

18. AHN, FC-M ${ }^{\circ}$ ULTRAMAR, 5344, Exp. 3.

19. AHN, FC-M ${ }^{\circ}$ HHACIENDA, 6089, Exp. 19.

20. AHN, FC-M ${ }^{\circ}$ IINTERIOR, 2103, Exp. 12.

21. AHN, FC-M﹎INTERIOR, 600, Exp. 37. 
Fomento y de Ultramar, dando este último las órdenes oportunas a los gobernadores generales de Cuba, Puerto Rico y Filipinas para que la adquiriesen ${ }^{22}$. Por el contrario, otras veces se suscitan controversias entre los departamentos ministeriales, como en el caso de varios militares que habían sido declarados inútiles por padecer enajenación mental y se hallaban internados en el manicomio de San Baudilio de Llobregat. El Ministerio de la Guerra se quejaba porque había tenido que sufragar su estancia en dicho centro durante seis meses con cargo a su presupuesto para evitar que la Junta del citado manicomio los expulsara, y exigía que el Ministerio de la Gobernación los trasladara a otro centro y se hiciera cargo de los gastos ocasionados ${ }^{23}$.

La existencia de numerosos expedientes de repatriación de súbditos españoles "dementes" que se encontraban internos en manicomios de otros países (Francia, Alemania, Estados Unidos de América) se explica por la renuncia de sus respectivos gobiernos a sufragar los gastos de estancia en dichos centros y, en algunos casos, por haber sido reclamados por sus parientes ${ }^{24}$.

Entre los fondos del Ministerio de Ultramar también encontramos noticias sobre discapacidades producidas por accidentes laborales. Es el caso del expediente promovido por la Junta de Obras del Puerto de Manila proponiendo la concesión de una pensión mensual vitalicia a favor de un trabajador de las obras del citado puerto, Juan Sequeña, el cual había quedado ciego e inútil por accidente ${ }^{25}$.

La documentación conservada en los fondos del AHN también permite acercarnos a un problema que sufrían un buen número de personas con discapacidad psíquica, su reclusión en instituciones penitenciarias sin recibir un tratamiento adecuado, como le sucedía a Juan Cossi, recluido en la prisión de Cádiz, aunque su caso se resolvió de manera favorable (1923-1924), pues fue excarcelado y trasladado a un manicomio ${ }^{26}$.

La constitución de unidades de inválidos en el ejército en el siglo XVIII tendrá continuidad en el siglo XIX y dará lugar a la creación de un Cuerpo de Inválidos en 1838. En la Sección de Diversos-Colecciones del AHN se conserva documentación relativa a estas unidades que procede del Archivo Histórico del Depósito de la Guerra, como una Real Orden sobre la formación de Compañías de Inválidos Inhábiles en 1816 y un expediente de 1821-1822 ${ }^{27}$. En esta misma Sección de Diversos se pueden espigar algunos documentos relacionados con la ayuda a mutilados e inválidos de guerra. En el archivo personal de Margarita Nelken, escritora y política republicana exiliada en México tras la Guerra Civil, encontramos informaciones sobre el dinero recaudado por esta en favor de la Liga de Mutilados e Inválidos de la Guerra de España ${ }^{28}$.

Finalmente, en la Sección de Universidades se puede encontrar documentación de interés acerca de las investigaciones académicas realizadas en la antigua Universidad Central sobre discapacidad, concretamente en la serie de expedientes académicos de alumnos. Por ejemplo, el expediente académico de José Coll Bofill, alumno de la Facultad de Medicina, contiene un ejemplar de su tesis doctoral titulada "La beneficencia pública y los sordos y sordomudos: influencia de la sordera sobre el desarrollo intelectual y sobre el lenguaje (ensayo clínico-fisiológico) (1904-1905)”29.

\footnotetext{
22. AHN, FC-M ${ }^{\circ}$ INTERIOR, 1447, Exp. 25

23. AHN, FC-M ${ }^{\circ}$ INTERIOR, 462, Exp. 7.

24. AHN, FC-M﹎ㄴtTRAMAR, 4748, Exp. 15 y 22; 4796, Exp. 8; 4689, Exp. 37; 4706, Exp. 38.

25. AHN, FC-M ${ }^{\circ}+$ ULTRAMAR, 508, Exp. 18.

26. AHN, FC-PRESID_GOB_PRIMO_DE RIVERA, 252-1, Exp. 65

27. AHN, DIVERSOS-COLECCIONES, 191, N. 2 y 193 N. 24.

28. AHN, DIVERSOS-TÍTULOS_FAMILIAS, 3236, N. 87 y 88.

29. AHN, UNIVERSIDADES, 4970, Exp. 13.
} 


\section{Referencias bibliográficas}

Andrés, L. (2018). Breve historia de las personas con discapacidad: de la opresión a la lucha por sus derechos. https://rebelion.org/docs/192745.pdf.

Burgos, E. (2005). Aproximación histórica al estudio del Colegio Nacional de Sordomudos y Ciegos de España. Revista Complutense de Educación, 16(1), pp. 183-193.

de la Cruz, L. M. (2003). La Sección de Clero del Archivo Histórico Nacional. En Galende, J. C. (Coord.), II Jornadas Científicas sobre Documentación de la Corona de Castilla (siglos XIII-XV) (pp. 373-432). Universidad Complutense de Madrid.

López, J. L. (2019). La conceptualización de la discapacidad a través de la historia: una mirada a través de la evolución normativa. Revista de la Facultad de Derecho de México, 69(273), pp. 835-855.

Maza, E. (1996). Pobreza y asistencia social en España, siglos XVI al XIX: aproximación histórica. Universidad de Valladolid.

Vergara, J. (2002). Marco histórico de la educación especial. Estudios sobre Educación, 2, pp. 129-143. 